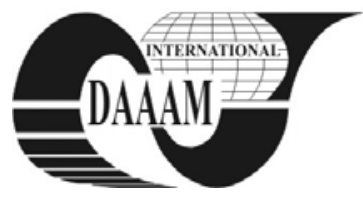

\title{
THEORETICAL AND EXPERIMENTAL RESEARCH FOR DENSE CONCRETE AS A SOUND ABSORBING MATERIAL
}

\author{
TODICA, G[eorgeta]; GARAI, M[assimo] \& ARGHIR, M[ariana]
}

\begin{abstract}
In this article are presented experimental and theoretical results for sound transmission loss through dense concrete partition are presented. The values measured under laboratory conditions are compared with the theoretical data. With the increase of outdoors noise levels the sound levels inside buildings are also increasing, focusing more and more attention on the need for better sound reduction of the building facades.
\end{abstract}

Key words: transmission loss, absorbing materials, reverberation room, sound pressure level, dense concrete

\section{INTRODUCTION}

The data presented in this paper are expressed in terms of sound transmission loss, which is equivalent to sound reduction index. Sound transmission loss data are given in the one-third octave bands between $50 \mathrm{~Hz}$ and $5000 \mathrm{~Hz}$.

A dense concrete material provides values of the sound transmission loss higher than other sound proofing materials of the same weight. Generally a partition will have better sound reduction with increasing frequency.

\section{THEORETICAL ASPECTS}

The sound transmission loss (R) of a partition depends on it`s mass, the stiffness and dimensions. If the stiffness can be ignored the transmission loss for an infinite partition for sound incident at an angle $\theta$, is given by (Beranek \& Vér, 1992):

$$
R(\theta)=10 \lg \left[1+\left(\frac{\omega \rho_{s}}{2 \rho c} \cos \theta\right)^{2}\right][d B]
$$

where $\rho_{\mathrm{s}}$ is the partition surface density $\left[\mathrm{kg} / \mathrm{m}^{2}\right]$; $\omega$ is the angular frequency $[\mathrm{rad} / \mathrm{s}]$; $\rho=1.21\left[\mathrm{~kg} / \mathrm{m}^{3}\right]$, is the density of the air; $\mathrm{c}=343\left[\mathrm{~m} / \mathrm{s}^{2}\right]$ is the speed of sound in the air.

$$
\rho_{s}=\rho_{m} \mathrm{~h}\left[\mathrm{~kg} / \mathrm{m}^{2}\right]
$$

where $\rho_{\mathrm{m}}$ is the density of the partition material $\left[\mathrm{kg} / \mathrm{m}^{3}\right]$ and $\mathrm{h}$ is the thickness of the partition [m].

The mass law equation predicts a $6 \mathrm{~dB}$ increase of the sound reduction index in case of doubling the thickness of the partition or of the frequency of the incident sound. The transmission loss will have the highest value for a normally incident sound, $\theta=0$.

At a frequency rate lower than the critical frequency $\left(\mathrm{f}_{\mathrm{c}}\right)$, relation (3), the transmission loss can be determined using the relation (1).

$$
\mathrm{f}_{c}=\frac{c^{2}}{2 \pi h} \sqrt{\frac{12 \rho\left(1-v^{2}\right)}{E}}[\mathrm{~Hz}]
$$

where $\rho$ is the density of the material $\left[\mathrm{kg} / \mathrm{m}^{3}\right] ; v$ is the Poisson coefficient and $\mathrm{E}$ is the Young's modulus of elasticity [GPa].

At normal incidence relation (1) becomes:

$$
R_{0}=10 \lg \left[1+\left(\frac{\omega \rho_{s}}{2 p c}\right)^{2}\right][d B]
$$

With a perfectly diffuse sound field and $\mathrm{R}_{0}>15 \mathrm{~dB}$, the argument of equation (1) may be averaged over a range of $\theta$ from 0 to $90^{\circ}$ to yield the random incidence transmission loss at low frequency:

$$
\mathrm{R}_{\text {random }}=\mathrm{R}_{0}-10 \lg \left(0.23 \mathrm{R}_{0}\right)[\mathrm{dB}]
$$

An expression for random incidence transmission loss at frequencies above the critical frequency was derived by Cremer (1942), (Fahy, 1993):

$$
\mathrm{R}_{\text {random }}=\mathrm{R}_{0}+10 \lg \left(\frac{f}{f_{c}}-1\right)+10 \lg \eta-2[\mathrm{~dB}]
$$

The dominant influence of the coincidence transmission is seen in the presence of the loss factor therm, $\eta$, dimensionless.

\section{LABORATORY MEASUREMENTS}

Measurements were done in the acoustics laboratory of the Department of Engineering for Energy, Nuclear and Environmental Control, University of Bologna, Italy.

All measurement methods used in this study are standardized (ISO 140/3, 1995), (ISO 10140/2, 2010).

The sound transmission loss of a dense concrete partition has been measured in laboratory by placing the element under test in an opening between two adjacent reverberant rooms. Noise level is produced into one of the rooms, the source room. Part of the sound energy is transmitted through the dense concrete partition into the other room, the receiving room. The values of the transmission loss are calculated with the following relation (ISO 10140/2, 2010):

$$
\mathrm{R}=\mathrm{L}_{1}-\mathrm{L}_{2}+10 \lg \frac{\mathrm{S}}{\mathrm{A}}[\mathrm{dB}]
$$

where $L_{1}$ - is the average sound pressure level in the source room, $[\mathrm{dB}]$;

$\mathrm{L}_{2}$ - is the average sound pressure level in the receiving room, [dB];

$\mathrm{S}=10.8 \mathrm{~m}^{2}$, the area of the test specimen;

$\mathrm{A}-$ is the equivalent sound absorbtion area in the receiving room, in square metres.

The sound absorbtion area in the receiving room can be determinated with the Sabine relation (Kuttruff, 2009): 


$$
\mathrm{A}=0.161 \frac{\mathrm{V}}{T_{\text {rev }}}\left[\mathrm{m}^{2}\right]
$$

where $\mathrm{V}=66.91 \mathrm{~m}^{3}$, is the receiving room volume and $\mathrm{T}$ is the measured reverberation time in the receiving room.

The dense concrete partition has as dimensions: $3.6 \mathrm{~m}$ length, $3 \mathrm{~m}$ width and $0.250 \mathrm{~m}$ thickness. The partition surface mass measured on $1 \mathrm{~m}^{2}$ is $370 \mathrm{~kg} / \mathrm{m}^{2}$.

The parameteres of the dense concrete partition are presented in table 1(Cremer et al., 2005):

Replacing the values from table 1 in the relation (3) the critical frequency can be obtained $82 \mathrm{~Hz}$.

At frequencies less than the critical frequency the transmission loss is obtained using the relations (4) and (5), and for frequency much higher than the critical frequency, the transmission loss is obtained by adapting relation (6) with the following equation:

$$
\mathrm{R}_{\text {random }}=\mathrm{R}_{0}+6 \lg \left(\frac{f}{f_{c}}-1\right)+6 \lg \eta-2[\mathrm{~dB}]
$$

Table 2 contains the measured and theoretical transmission loss values as a function of frequency for the dense concrete partition:

Figure 2 illustrates the theroretical and measured values for the transmission loss. In the area of the critical frequency the difference between the measured and the theoretical values reaches it`s maximum distance.

Figure 2 illustrates the theroretical and measured values for the transmission loss. In the area of the critical frequency the difference between the measured and the theoretical values reaches it's maximum distance. At high frequencies the measured values cannot go over $60 \mathrm{~dB}$, due to practical limitations of the test facilities.

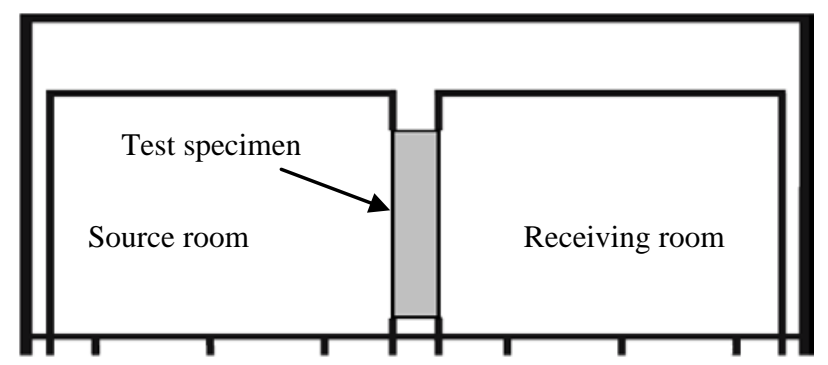

Fig. 1. Reverberation room for measurement transmission loss

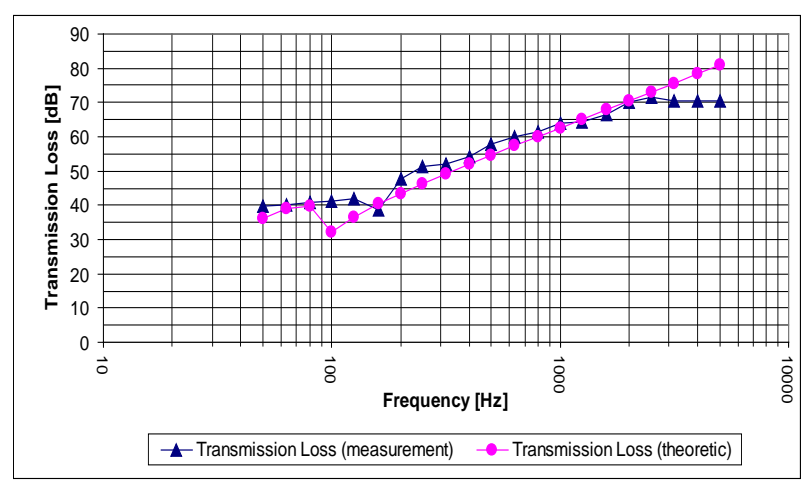

Fig. 2. Transmission loss measurements and theoretical values for the dense concrete partition.

\begin{tabular}{|c|c|c|c|}
\hline $\begin{array}{c}\text { Young's modulus } \\
\text { of elasticity } \\
{\left[\mathbf{N} / \mathbf{m}^{2}\right]}\end{array}$ & $\begin{array}{c}\text { Poisson } \\
\text { coefficient }\end{array}$ & $\begin{array}{c}\text { Loss } \\
\text { factor }\end{array}$ & $\begin{array}{c}\text { Density } \\
{\left[\mathbf{k g} / \mathbf{m}^{\mathbf{3}}\right]}\end{array}$ \\
\hline $22.8 \cdot 10^{9}$ & 0.15 & 0.004 & 2300 \\
\hline
\end{tabular}

Tab. 1. Parameters values for the dense concrete partition.

\begin{tabular}{|c|c|c|}
\hline $\begin{array}{c}\text { Frequenc } \\
\text { y [Hz] }\end{array}$ & $\begin{array}{c}\text { Transmission loss } \\
\text { (measurement) } \\
\text { [dB] }\end{array}$ & $\begin{array}{c}\text { Transmission loss } \\
\text { (theoretic) [dB] }\end{array}$ \\
\hline 50 & 39.6 & 36.1 \\
\hline 63 & 40.2 & 38.9 \\
\hline 80 & 40.7 & 39.8 \\
\hline 100 & 41.2 & 32.3 \\
\hline 125 & 41.9 & 36.6 \\
\hline 160 & 38.6 & 40.4 \\
\hline 200 & 47.6 & 43.3 \\
\hline 250 & 51.5 & 46.2 \\
\hline 315 & 52.1 & 49 \\
\hline 400 & 54.2 & 51.9 \\
\hline 500 & 57.7 & 54.6 \\
\hline 630 & 60.1 & 57.3 \\
\hline 800 & 61.5 & 60.1 \\
\hline 1000 & 64.1 & 62.7 \\
\hline 1250 & 64.3 & 65.2 \\
\hline 1600 & 66.4 & 68.1 \\
\hline 2000 & 70.1 & 70.6 \\
\hline 2500 & 71.5 & 73.1 \\
\hline 3150 & 70.4 & 75.7 \\
\hline 4000 & 70.4 & 78.4 \\
\hline 5000 & 70.4 & 80.9 \\
\hline 2.4 & & \\
\hline
\end{tabular}

Tab. 2. Measured and theoretical transmission loss values for the dense concrete partition.

\section{CONCLUSIONS}

The analisys of the measurement data and the theoretical values shows a good correlation degree. The transmission loss values for a dense concrete partition increase as the frequency increases.

\section{AKNOWLEDGEMENTS}

The first author (Georgeta Todica) would like to thank the acoustics laboratory of the Department of Engineering for Energy, Nuclear and Environmental Control (DIENCA), University of Bologna, Italy for the support and help with the measurements.

This paper was supported by the project "PRODOC" contract no. POSDRU 6/1.5/S/5, project co-funded by the European Social Found through the Sectorial Operational Program Human Resources 2007-2013.

\section{REFERNCES}

Beranek, L. \& Vér I., (1992). Noise and Vibration Control Engineering, Principles and Applications, John Wiley \&Sons, Inc., ISBN 07-004841-X, New York

Cremer, L.; Heckl, M. \& Petersson, B.(2005). Structure-Borne Sound, Springer, ISBN 3-540-22696-6, Berlin

Fahy, F., (1993). Sound and Structural Vibration, Radiation, Transmission and Response, Academic Press, ISBN 0-12247670-0, London

ISO 140/3, (1995). Acoustics. Measurement of sound insulation in buildings and of building elements. Part 3: Laboratory measurements of airborne sound insulation of building elements

ISO 10140/2, (2010). Acoustics. Laboratory measurements of sound insulation of building elements. Part 2: Measurement of airborne sound insulation

Kuttruff, H., (2009). Room Acoustics, Fifth Edition, Taylor and Francis Group, ISBN 0-203-87637-7, London 